\title{
The TOGAF Based Governance Framework Proposition for Technology Management Systems
}

\author{
Nermin Sökmen \\ The Scientific and Technological Research Council of Turkey (TÜBITAK), Gebze, Turkey \\ Informatics and Information Security Research Center (BILGEM), Gebze, Turkey
}

\begin{abstract}
A computer-based technology management system is needed to manage technology assessment, technology acquisition, and technology planning capabilities to shape and accomplish the strategic and operational objectives of an organization. During the design of technology management intelligence, it has appeared that there has been a need to establish an integrated and systematic approach. The Open Group Architecture Framework (TOGAF) provides this systematic approach to the planning, development, implementation, and governance of the enterprise architecture. This exploratory paper examines the TOGAF approach to develop a technology management architecture in a product development organization. The paper discusses the development and proactive governance of the technology management architecture from various perspectives such as architecture capability, architecture development, transition planning, and architecture implementation. The paper presents a TOGAF based governance framework for the technology management system in an organization that develops software-intensive systems. The framework supports an iterative approach in the architecture capability, architecture development, transition planning, and architecture implementation phases. The implementation governance phase can deal with multiple projects simultaneously. Therefore, the framework suggests applying agile system development principles to the projects that develop and deploy the architecture-compliant technology management solutions. The proposed framework helps organizations to design and implement a technology management architecture that meets the needs of the business. The framework also aims to simplify development and maintenance processes of a technology management system.
\end{abstract}

Keywords: technology management, enterprise architecture, TOGAF, ADM, computer-based system, governance framework

\section{Introduction}

Technology management is defined as collaboration of "engineering, science, and management disciplines to plan, develop, and implement technological capabilities to shape and accomplish the strategic and operational objectives of an organization" (National Research Council, 1987). Technology utilization, knowledge management, technology acquisition, technology integration, technology assessment, and technology planning and forecasting are some of technology management activities (Çetindamar, Can, \& Pala,

Nermin Sökmen, chief senior researcher, Ph.D., The Scientific and Technological Research Council of Turkey (TÜBITAK), Gebze, Turkey;Informatics and Information Security Research Center (BILGEM), Gebze, Turkey.

Correspondence concerning this article should be addressed to Nermin Sökmen, Informatics and Information Security Research Center (BILGEM), Gebze, Kocaeli 41470, Turkey. 
2006). The common feature of all these activities is that they require both data and domain-specific decision-making algorithms and methods. Technological advances in computer-based Information Technologies (IT) facilitate technology management processes (Linn, Zhang, \& Li, 2000). IT enables organizations to establish a more robust, resilient, intelligent, and automated processe for a technology management framework. Therefore, organizations desperately need an architectural framework when implementing and maintaining an enterprise-wide technical infrastructure for the support of technology management system.

The management of technology management activities requires a different approach to achieving interoperability between the technology management system and the rest of the business. An integrated and systematic approach is needed, where development, implementation, and operation of the system are guided by strategic and tactical business objectives. More importantly, technology management system can be continuously updated and extended by new requirements of end users. In such circumstances, there is a need for an effective governance framework to establish and sustain a technology management environment. TOGAF provides this systematic approach to the planning, development, implementation, and governance of the enterprise information architecture (The Open Group, 2011). The management of technology management activities requires an integrated and systematic approach to sustaining the strategies and objectives of the organization.

In this paper, TOGAF approach is examined in order to develop technology management architecture in a product development organization. This paper presents a high level conceptual framework that integrates business objectives into the computer-based technology management system. The framework catches both bottom-up and top-down changes occur during the design, development, maintenance, and operations of technology management applications. The paper includes five sections. The introduction section discusses the fundamental features of a technology management system. The research method highlights the TOGAF approach. The research results section introduces the TOGAF based governance framework for technology management systems. The development and proactive governance of the technology management architecture are discussed from various perspectives such as architecture capability, architecture development, transition planning, and architecture implementation. Consequently, the paper proposes a TOGAF based governance model for the technology management system in an organization that develops software-intensive systems. The organizational structure and business processes should support the new approach. Therefore, the paper also focuses on the need for organizational change.

\section{Literature Review}

The Management of Technology (MOT) discipline encompasses a large number of disciplines including, but not limited to, project management, strategic management, innovation theory, and technology philosophy (Drejer, 1997). According to Huijiong (1993), planning for the development of technology capabilities, identifying key technologies, making "buy or make" decisions, and establishing institutional mechanisms for management of the development of technology capabilities are four fundamental technology management activities (Liao, 2005). Çetindamar, Phaal, and Probert (2009) grouped technology management activities under six main headings: identification, selection, acquisition, exploitation, protection, and learning. While technology identification deals with search, auditing, data collection, and intelligence processes, technology selection focuses on decision-making activities to assess or appraise capacity based on relevant strategic issues. Technology acquisition is another decision-making process that creates three basic choices: technologies might 
be developed internally, in some form of collaboration, or acquired from external developers. Linn et al. (2000) introduced an object-oriented intelligent management system for technology management in order to enhance automation in technology management. The system is organized into two layers, namely, management layer and operation layer. While the management layer administrates the overall system activities, the operation layer manages domain-specific expert system activities, such as technology development planning.

Technology assessment is a vital part of technology management. It aims to establish an early warning system to detect, control, and direct technological changes to maximize benefit (Cetron \& Connor, 1972; Van Den Ende, Mulder, Knot, Moors, \& Vergragt, 1998). Chestnutwood and Levin (1999) introduced The Technology Assessment and Management (TeAM) methodology that aims to support decision makers by providing various tools to determine product replacement, technology insertions, and upgrade decisions over the life of the system. Technology capability is another important part of technology management. Technology capability is the capability to make effective use of technical knowledge and skills (Jin \& Zedtwitz, 2008). Panda and Ramanathan (1996) classified technological capability under three headings, namely, strategic technological capabilities, tactical technological capabilities, and supplementary technological capabilities. Asian and Pacific Center for Technology Transfer (1989) developed a technological capability assessment methodology called Technology Atlas. Technology Atlas evaluated the capability of technology under four headings: Technoware, Infoware, Humanware, and Orgaware (Alizadeh, 2012).

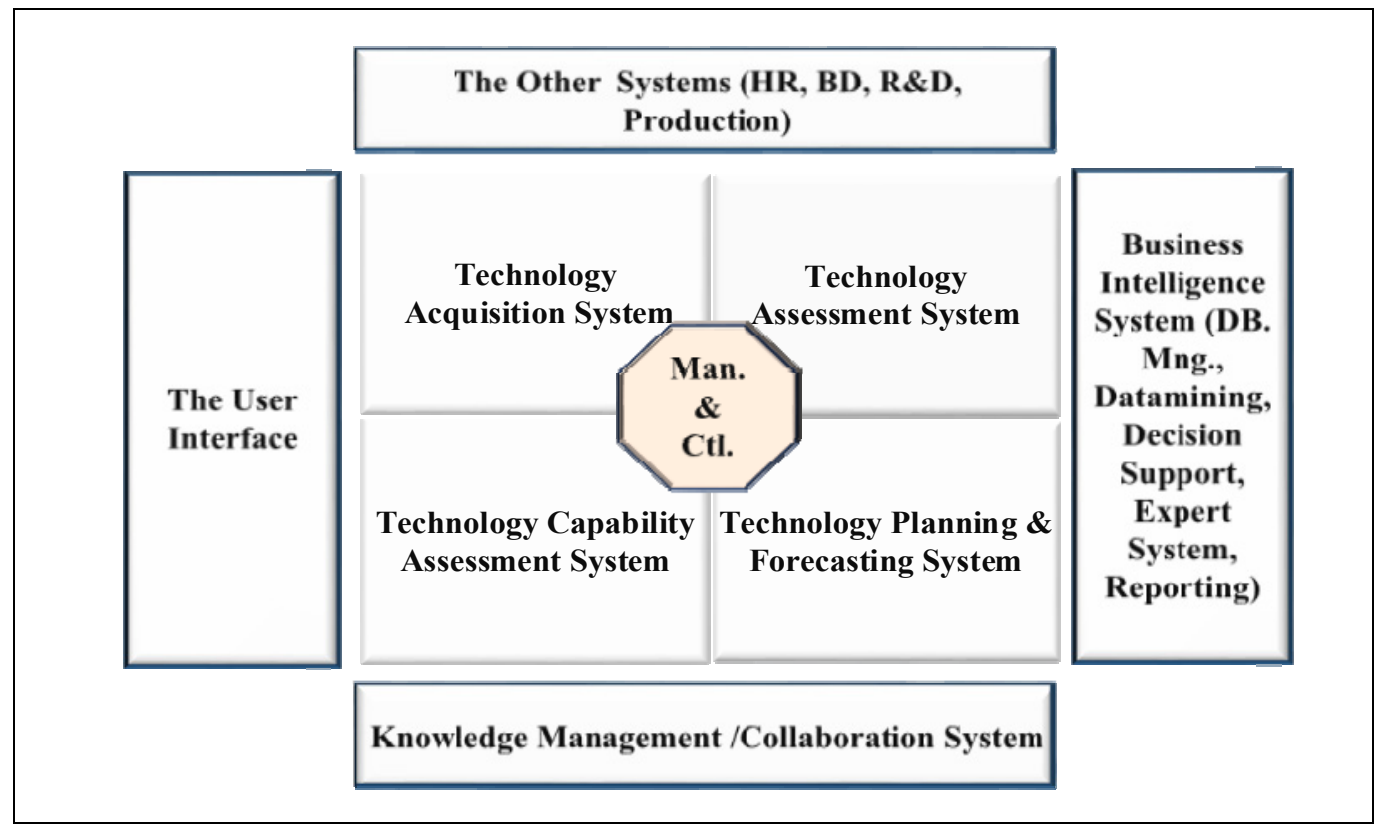

Figure 1. Computer-based technology management system.

In this research, a Technology Management System (TMS) is introduced based on basic requirements of technology management principles. The TMS system illustrated in Figure 1 is an integral part of computer-based information system that supports technology management related business processes, information flows, data analytics, and reporting in a product development organization. TMS includes technology capability assessment system, technology acquisition system, technology assessment system, and technology planning and forecasting system. It aims to support business decision-making activities in technology management domain. TMS is not a stand-alone business entity. It shares data or applications with 
other systems such as Human Resources (HR), production, Product Development (PD), and Business Development (BD). It also provides user interfaces that allow the user to manage activities and events related to technology management. All groups in the Technology Management Enterprise (TME) should be involved in the development, maintenance, and operation of the information environment.

\section{Research Method}

A firm should have the ability to integrate commercial and technological functions in order to establish effective technology management approach (Phaal, Farrukh, \& Probert, 2006). In fact, technology management requires an integrated perspective that aligns technology strategy with business strategy and coordinates the research, development, production, human resources, marketing, and other functions of the firm (Drejer, 1997). A technology or product development organization requires a framework that covers a formal description of the TMS with its components and interfaces, a set of guidelines, templates, and standards which are required to establish and maintain the TME architecture practice within the organization. The framework must ensure that TMS sustains and extends the strategies and objectives of the organization. It must help the organization keep up with emerging opportunities. The framework must create an environment that identifies essential software applications and hardware changes in order to support new requirements arising from current and future business needs. This paper applies the TOGAF approach in order to address these three fundamental issues (compliance with the strategy, management of change and management of requirements) explained above. The TOGAF is used as a framework to develop and maintain enterprise architecture with TMS solutions. It places the requirement management process at the center of Architecture Development Method (ADM) in order to maintain traceability between requirements and the architectural structures (Engelsman, Jonkers, \& Quartel, 2010).

The literature review shows a limited number of studies on the TOGAF framework. Kabzeva, Niemann, Mueller, and Steinmetz (2010) applied the TOGAF ADM to a large-scale SOA-based research project in order to support the governance proposes in the context of a service marketplace. Chaczko, Kohli, Klempous, and Nikodem (2010) presented the smart hospital system solution that used the TOGAF ADM. While Zadeh, Millar, and Lewis (2012) analyzed the business principles of the TOGAF according to the principles of cybernetics, Leist and Zellner (2006) evaluated the TOGAF and other well-known architecture frameworks regarding their contribution to support architecture development projects. Unlike the studies in the literature, this paper applies the TOGAF framework to the development and implementation of technology management processes.

\section{Research Results}

\section{The TOGAF Based Governance Framework for TMS}

During the design of a computer-based technology management system, the product development organization needed organizational structures, processes, principles, and standards that ensure that the TME sustains the strategies of the organization and accomplishes the needs of end users and stakeholders. This paper uses the TOGAF ADM lifecycle to develop and manage TMS enterprise architecture. Figure 2 shows phases of the TOGAF ADM lifecycle. The ADM starts with a preparation and initiation phase called Preliminary Phase. TMS enterprise, architecture principles, and the relationship between other management frameworks are defined in Preliminary Phase. Enterprise in technology management concept is an organization that has established a culture of technology management in the company, implemented computer-based technology 
management system, and continuously managed the technology management related processes and activities. Technology management activities must be aligned with the business objectives. Data which is retrieved, processed, used, and stored in TMS is an important asset and needs proper management.

TME architecture development lifecycle is started with "Request for Architecture Work" document from sponsor to TME executive. Architecture Vision phase identifies the key stakeholders and their objectives. TME retrieves data from the $H R, R \& D$, and production departments to evaluate dynamic capabilities in technology and product development; from the marketing and BD departments to assess and plan the key technologies and to make proper technology acquisition decisions. Therefore, the HR, R\&D, production, marketing, and BD departments are the key stakeholders of TME. This phase also identifies the key business requirements to be taken account during the development of business, information system, and technology architectures. Assessing performance of business capability based on technology development capability, selecting the appropriate technology acquisition mode based on business capabilities, tracking and assessing current and future technology to be used as a critical asset in the growth of business, planning technical evaluation of the product line or product platform in the business, and minimizing the TMS OPEX (OPerating EXpense) are some of the key business requirements.

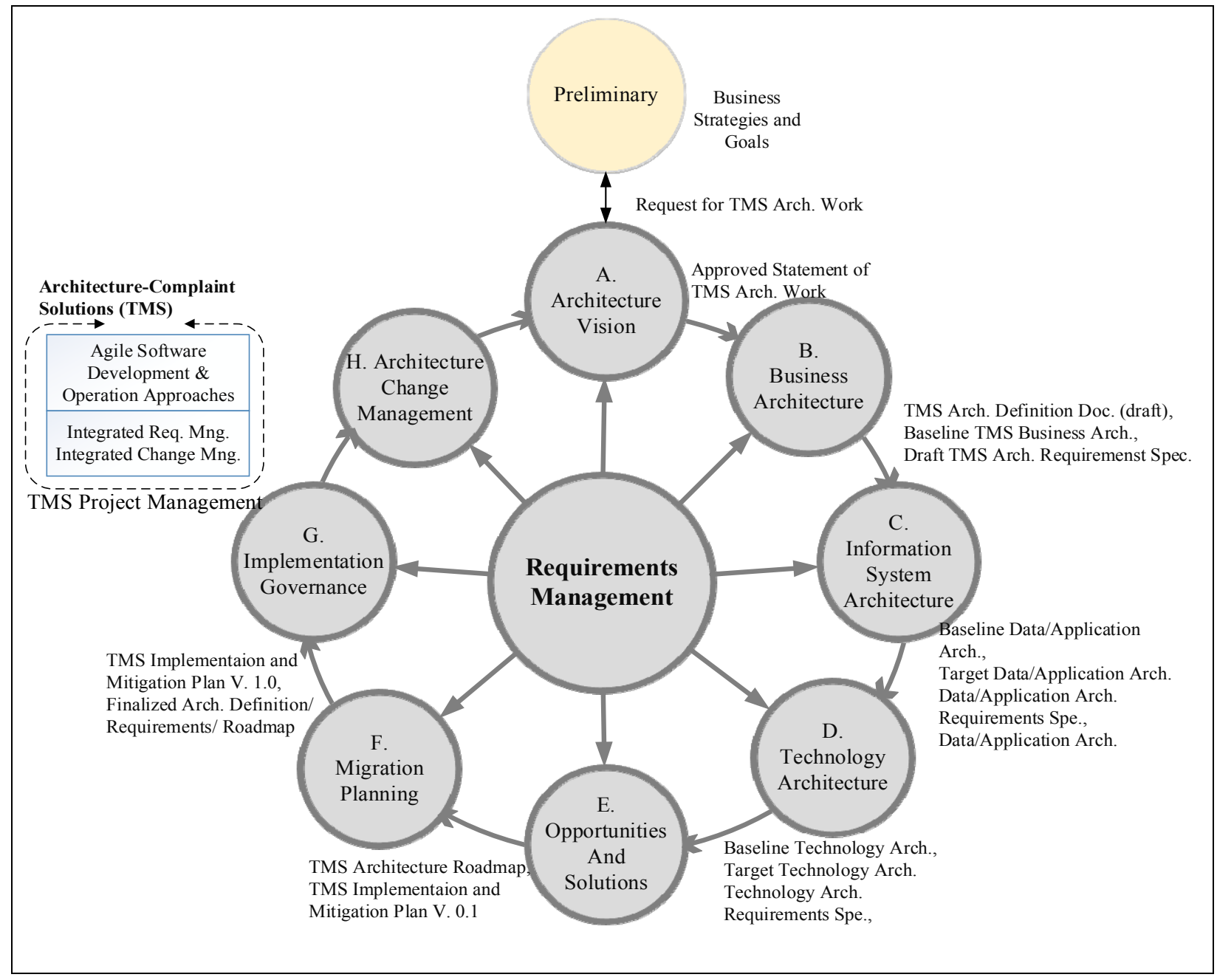

Figure 2. The TOGAF ADM lifecycle (The Open Group, 2011). 
The TOGAF framework supports four architecture domains, namely, the business architecture, the data architecture, the application architecture, and the technology architecture. The architecture development phases follow the same steps: 1) select reference models, viewpoints and tools, 2) develop baseline architecture description, 3) develop target architecture description, 4) perform gap analysis, 5) define candidate roadmap components, 6) resolve impacts across the architecture landscape, 7) conduct formal stakeholder review, 8) finalize the business architecture, and 9) create architecture definition document (The Open Group, 2011). The Target Business Architecture of TMS is developed based on the information given in the Architecture Vision, including business requirements and business scenarios. For each subsystem of TMS, the high level business requirements are decomposed into the more detail lower level requirements and business models are created from the business scenarios given in the Architecture Vision document. The business strategy, governance, organization, key business processes, and information are described in the business architecture domain. Business architecture phase aims to define the requirements of the following domains. The Business Architecture of TMS and the Architecture Vision are used to develop the Target Data Architecture, the Target Application Architecture, and the Target Technology Architecture.

The TSM architecture roadmap gives a high level view of the target architecture and presents work packages in a timeline diagram. The Implementation and Migration Plan provides the activities necessary to realize the TSM architecture roadmap and the schedule of TMS development projects. The TMS architecture roadmap and the implementation and migration plan are generated during the transition planning phases.

The TOGAF based TMS governance framework aims to develop and maintain a technology management intelligence dealing with knowledge management, technology capability assessment system, technology acquisition system, technology assessment system, technology planning, and forecasting system and management and support system activities. Figure 3 illustrates the TOGAF based governance framework for TMS enterprise. The framework suggests an iterative approach in the architecture capability (Phase A), architecture development (Phase B, C, \& D), transition planning (Phase E \& F), and architecture implementation (Phase $\mathrm{G} \& \mathrm{H}$ ) phases. Each cycle can run several iterations in order to complete business requirements and business scenarios and to develop an adequate and sufficient business, data, application, and technology architectures required for the implementation. The implementation governance phase can carry out multiple projects simultaneously to develop and deploy the architecture-compliant TMS solutions. The framework hardly suggests applying agile system development principles and practices to the implementation governance phase. This iterative and incremental development style brings some advantages such as continuous improvement, rapid and flexible respond to change and early delivery.

Architecture change management phase recognizes not only bottom-up changes occur during the development, maintenance, and operations of TMS applications but also strategic, top-down directed changes to influence TMS capability (The Open Group, 2011). The framework applies the defined change management processes, environment, and tools in the organization to manage changes. It promotes an integrated change management approach to combine and manage changes in the architecture capability, architecture development, planning, and architecture implementation phases. The framework also uses the defined requirement management processes, environment, and tools in the organization to manage architectural requirements identified during the execution of each ADM phase. The requirements management and change management processes work together to ensure the proper management of change in architectural requirements. 


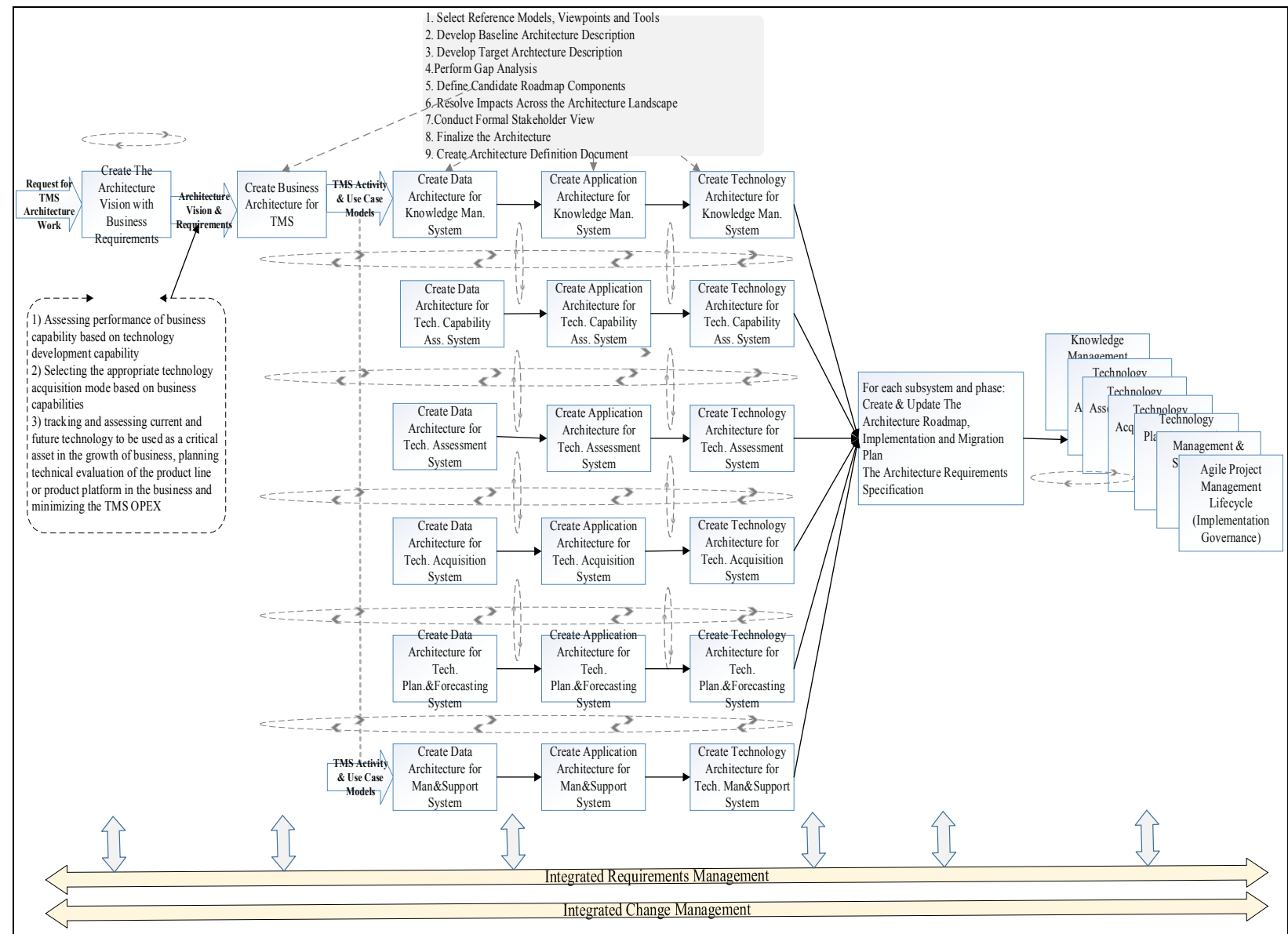

Figure 3. The TOGAF based governance framework for TMS.

\section{Organization Structure of TMS Architecture Governance Framework}

TMS enterprise architecture created, managed, and controlled by TOGAF ADM requires an adequate organizational structure in order to support all governance activities. Developing and operating the TMS enterprise architecture is not a solitary activity. TME executive needs to cooperate with the sponsor who is responsible for financially authorizing the TMS architecture, creating Request for Architecture Work, and approving the final work. TME executive also cooperates with the end users and the stakeholders who are responsible for reviewing the outputs of each ADM phase. TME executive is responsible for managing and leading across functional teams of TMS architects, IT technical support personnel, system and software engineers, and domain experts. TME executes assign tasks and responsibilities of the functional team members. They have responsibility for the overall success of the entire enterprise. The TMS architecture board members consists of 1) architects for enterprise architecture, business architecture, data architecture, application architecture, and technology architecture; 2) project managers; 3) system and software engineers; 4) IT technical support personnel; and 5) domain experts. The roles of Architecture Board members are grouped under seven categories: decision-making, architect, project manager, IT support, system and software developer, reviewer, and expert. Board members may take differing roles and responsibilities depending on their technical and domain experience. The fundamental relationship among sponsor, end users, stakeholder, the TME executive, and architecture board is illustrated in Figure 4. 


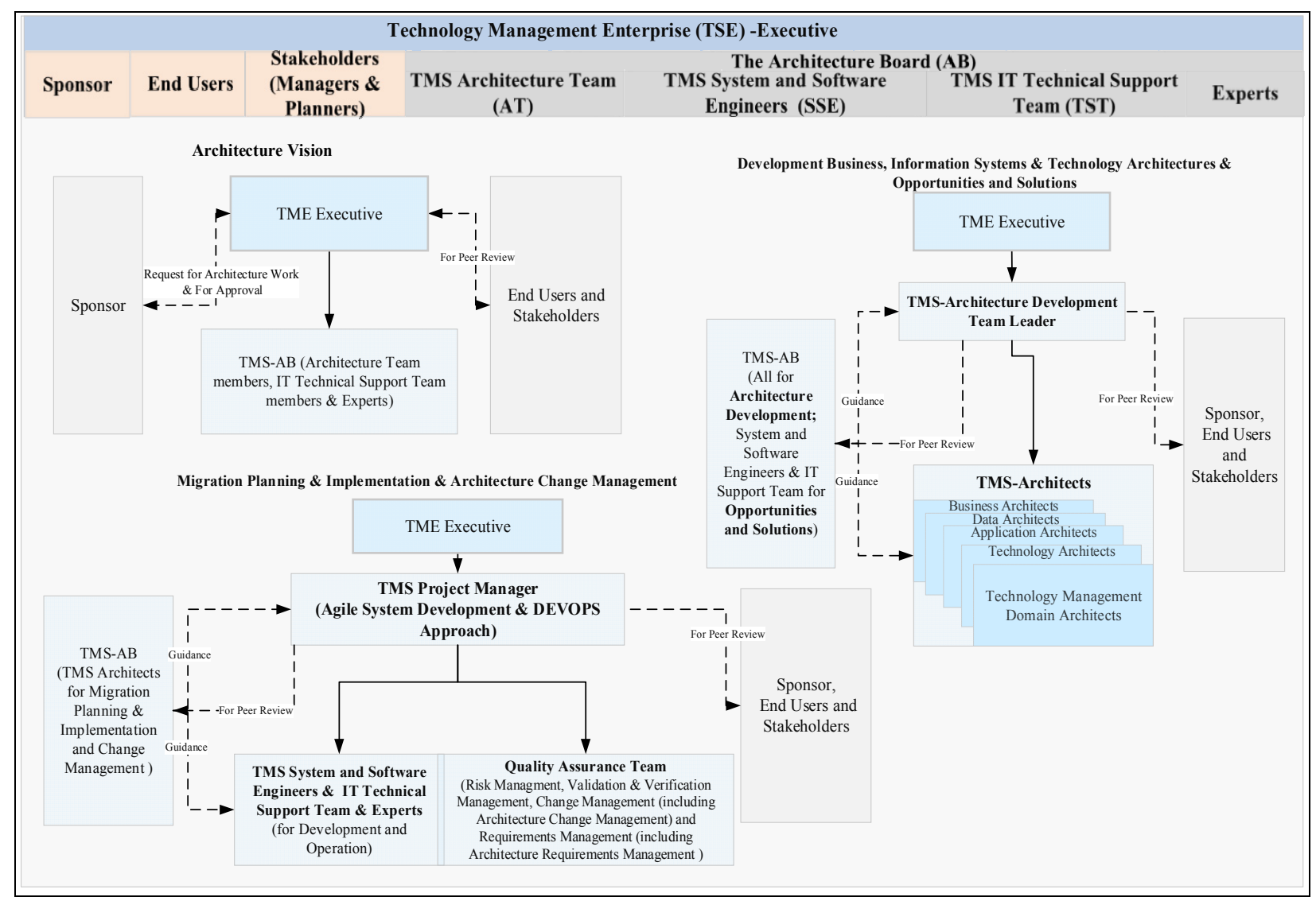

Figure 4. Organization structures of TMS architecture governance framework.

\section{Conclusions}

The paper presented a computer-based TMS that consisted of knowledge management system, technology capability assessment system, technology acquisition system, technology assessment system and technology planning and forecasting system, and management and support system. TMS supports all business decision-making activities in technology management domain. The management of technology management activities requires an integrated and systematic approach to sustain the strategies and objectives of the organization. The paper examined the TOGAF approach to establish a technology management architecture in a product development organization. The proposed framework uses an iterative approach in the architecture capability, architecture development, transition planning, and architecture implementation phases. It can perform several iterations in each cycle in order to develop business, data, application, and technology architectures. The framework also recommends applying agile system development principles to the system and software implementation (implementation governance) phase. The framework also suggests the integrated change management and integrated requirements management processes. The requirements management and change management processes must work together in order to ensure the proper management of change in architectural requirements.

\section{References}

Alizadeh, Y. (2012). Firm-level technological capability assessment; a literature review. In Technology Management Conference (ITMC), 2012 IEEE International (pp. 398-404). IEEE. 
Cetindamar, D., Can, Ö., \& Pala, O. (2006). Technology management activities and tools: The practice in Turkey. In Technology Management for the Global Future, 2006. PICMET 2006 (Vol. 1, pp. 92-98). IEEE.

Cetindamar, D., Phaal, R., \& Probert, D. (2009). Understanding technology management as a dynamic capability: A framework for technology management activities. Technovation, 29(4), 237-246.

Cetron, M. J., \& Connor, L. W. (1972). A method for planning and assessing technology against relevant national goals in developing countries. In M. J. Cetron and B. Bartocha (Eds.), The methodology of technology assessment. New York: Gordon and Breach.

Chaczko, Z., Kohli, A. S., Klempous, R., \& Nikodem, J. (2010). Middleware integration model for smart hospital system using the open group architecture framework (TOGAF). In Intelligent Engineering Systems (INES), 2010 14th International Conference on (pp. 215-220). IEEE.

Chestnutwood, M., \& Levin, R. (1999). Technology assessment and management methodology-an approach to system life sustainment and supportability enhancement. In Digital Avionics Systems Conference, 1999. Proceedings. 18th (Vol. 1, pp. 1-A). IEEE.

Drejer, A. (1997). The discipline of management of technology, based on considerations related to technology. Technovation, 17(5), 253-265.

Engelsman, W., Jonkers, H., \& Quartel, D. (2010). Supporting requirements management in TOGAFTM and ArchiMate ${ }^{\circledR}$. White Paper, The Open Group.

Huijiong, W. (1993). Technology management in a dual world. International Journal of Technology Management, 8(1-2), 108-120.

Jin, J., \& Von Zedtwitz, M. (2008). Technological capability development in China's mobile phone industry. Technovation, 28(6), 327-334.

Kabzeva, A., Niemann, M., Mueller, P., \& Steinmetz, R. (2010). Applying TOGAF to define and govern a service-oriented architecture in a large-scale research project. In AMCIS (p. 356).

Leist, S., \& Zellner, G. (2006). Evaluation of current architecture frameworks. In Proceedings of the 2006 ACM Symposium on Applied Computing (pp. 1546-1553). ACM.

Liao, S. H. (2005). Technology management methodologies and applications: A literature review from 1995 to 2003. Technovation, 25(4), 381-393.

Linn, R. J., Zhang, W., \& Li, Z. Y. (2000). An intelligent management system for technology management. Computers \& Industrial Engineering, 38(3), 397-412.

The Open Group. (2011). TOGAF ${ }^{\mathrm{TM}}$ Version 9.1-A pocket guide. Retrieved from www2.opengroup.org

Panda, H., \& Ramanathan, K. (1996). Technological capability assessment of a firm in the electricity sector. Technovation, 16(10), 561-588.

Phaal, R., Farrukh, C. J., \& Probert, D. R. (2006). Technology management tools: Concept, development and application. Technovation, 26(3), 336-344.

US National Research Council. (1987). Management of technology the hidden competitive advantage. Washington National Academy Press. Retrieved from http://www.referenceforbusiness.com/management/Str-Ti/Technology-Management.html\#ixzz42xELSnir

Van Den Ende, J., Mulder, K., Knot, M., Moors, E., \& Vergragt, P. (1998). Traditional and modern technology assessment: Toward a toolkit. Technological Forecasting and Social Change, 58(1), 5-21.

Zadeh, M. E., Millar, G., \& Lewis, E. (2012). Mapping the enterprise architecture principles in TOGAF to the cybernetic concepts-An exploratory study. In System Science (HICSS), 2012 45th Hawaii International Conference on (pp. 4270-4276). IEEE. 